\title{
Interaction Between a Soil Fungus and Barley Seed
}

\author{
By J. M. LYNCH AND S. J. PRYN \\ Agricultural Research Council, Letcombe Laboratory, Wantage, Oxfordshire $O X_{12}{ }_{9} J T$
}

(Received 2 June 1977; revised 8 July 1977)

\section{INTRODUCTION}

Germination and seedling establishment can be poor when seeds are drilled into soils and come into close contact with straw, particularly when the soil is wet and simplified methods of cultivation such as direct drilling are used (Ellis, Barber \& Graham, 1975). Micro-organisms can use the straw as substrates to form phytotoxic products (McCalla \& Norstadt, 1974; Lynch, 1976) but seemingly the dense proliferation of fungal mycelium which can develop on such substrates (Lynch, 1975) might also physically affect the seeds. The purpose of the present investigation was to determine whether one common soil fungus, Gliocladium roseum, which occurs on rotting plant residues (Domsch \& Gams, 1972), affects the germination of barley seeds.

\section{METHODS}

Inoculum. Gliocladium roseum Bain (IMII96507) was isolated on agar containing an extract of barley residues, and identified at the Commonwealth Mycological Institute. It was maintained on malt extract agar and cultured in $250 \mathrm{ml}$ flasks containing malt extract broth (100 ml) on a rotary shaker (200 rev. $\mathrm{min}^{-1}$ ) at $25^{\circ} \mathrm{C}$ in the dark. The fungal suspension was centrifuged at $1000 \mathrm{~g}$ and washed three times with distilled water; seeds of barley, Hordeum vulgare var. Proctor, were soaked in the resulting preparation of mycelium and conidia for $5 \mathrm{~min}$. When the effect of inoculum density was studied, the fungal suspension was diluted with distilled water. In one experiment, the lemma and palea, the outer coat of the seed (husk), were removed after $4 \mathrm{~h}$ of imbibition and prior to inoculation.

Measurement of seed germination and seedling growth. Seeds of barley were pressed into the surface of moistened sand in glass Petri dishes ( $14 \mathrm{~cm}$ diam.). For each treatment three plates each containing 10 seeds were used. The percentage germination and, in some experiments, the extension of roots and coleoptiles were assessed after 5 days in the dark at $20^{\circ} \mathrm{C}$. To test the effect of oxygen, seeds were placed on moistened sand in 21 conical flasks ( 30 seeds per flask) and flowmeters were used to regulate the supply of oxygen and nitrogen to the flasks.

Assessment of viability. To investigate the relationship between fungal inhibition of seed germination and seed death, seeds were treated with the fungus and left in moistened sand for various lengths of time. The seed husk and any visible fungal mycelium were removed before assessing germination of the seed on sand.

The viability of seeds exposed to various periods of anaerobiosis was assessed with seeds which had been surface-sterilized by soaking in a $12 \%(\mathrm{v} / \mathrm{v})$ aqueous sodium hypochlorite for $2 \mathrm{~min}$, pressure being reduced for half this period (Barber, 1967), then washed six times for $5 \mathrm{~min}$ in sterile distilled water, and dried overnight in a sterile desiccator. These seeds were placed in sterile distilled water through which nitrogen was bubbled. At intervals, 30 seeds were removed and their ability to germinate on moistened sand within 5 days was assessed.

Analysis of seed exudates. One hundred surface-sterile barley seeds were added to $10 \mathrm{ml}$ of a sterile dilute mineral solution (Lynch, 1977a) in a $100 \mathrm{ml}$ flask. Mixtures of air and nitrogen were made using flowmeters, and the gases were sterilized with a filter and bubbled through a Dreschel bottle containing sterile mineral solution to saturate them with water vapour, before being passed into the flask containing the seeds. The composition of the effuent gases was checked by gas chromatography (Smith \& Dowdell, 1973). At intervals, samples $(5 \mathrm{ml})$ of the solution in the flask were taken for analysis of soluble carbon compounds as described by Gunn (1975). The mineral solution in the Dreschel bottle was also analysed to ensure that negligible 
quantities of these substances had entered the system in the gas stream. After each sampling, solution from the Dreschel bottle was added to the flask to keep the solution in the latter at constant volume.

\section{RESULTS}

\section{Effect of inoculum density}

Gliocladium roseum rapidly colonized barley seeds at the end of the seed closest to the embryo. Inoculum densities of $\mathrm{I}, 5$ and $7 \mathrm{~g} \mathrm{l}^{-1}$ inhibited germination by 20,70 and $90 \%$ respectively.

Although germination was suppressed while the fungus remained on the seeds, some time elapsed before they were killed. After 3 days colonization, there was little effect on seed viability; in 7 days it was reduced to $40 \%$ and it took 10 days to kill all seeds.

\section{Substrates for microbial colonization}

The time-course of exudation into solutions saturated with air was studied. A large quantity of exudate was released during imbibition $\left(8 \mu \mathrm{g}_{\text {carbon seed }}{ }^{-1} \mathrm{~h}^{-1}\right)$ which probably corresponds to the rehydration of membranes (Simon, 1974). Within I h the rate of exudation decreased by a factor of 4 , reached a steady state for at least $48 \mathrm{~h}$ and was the same at $\mathrm{pH} 3.2$ and $\mathrm{pH} 6$, the $\mathrm{pH}$ range in which these seeds germinated normally. In low concentrations of oxygen the initial flux of exudation was not affected but the steady state production was increased (Table 1). The flow of exudates appeared to be related to their concentration in the surrounding medium; continuous removal of the exudates increased the flow.

\section{Competition between fungi and seeds for oxygen}

Entry of oxygen into the seed was investigated with seeds which had imbibed so that they had sufficient moisture to germinate. These seeds were sealed in various regions with silicone grease to provide a barrier to oxygen diffusion. Whereas the silicone exerted no toxic effect on the seed directly, coating of the seed at the tip nearest to the embryo, i.e. the position of fungal colonization, reduced germination by $90 \%$. After the husks of seeds were removed, no such inhibition in germination was found.

Lowering the concentration of oxygen reduced the percentage germination of seeds (Fig. I). When the fungus was present, the germination was reduced still further. For example, whereas anaerobiosis was necessary to completely prevent germination in the absence of the fungus, in its presence an oxygen concentration of between 7 and $12 \%$ was sufficient. When seeds were subjected to anaerobiosis in the absence of the fungus for I day their viability was reduced to $67 \%$, but none was able to survive the treatment for more than 5 days.

\section{DISCUSSION}

The growth of the fungus on the seed depends on the supply of a carbon source, which could be provided either by soluble exudates from the seed or by the components of its husk. The very rapid localized colonization suggests that soluble substrates are used by the fungus. Pearson \& Parkinson (I96I) demonstrated that ninhydrin-positive substances were initially excreted from around the embryo (the micropylar region) of the broad bean seed and if this were also true for barley it would explain the fungal colonization of the seed in that area. The size and shape of the barley seed make it difficult to establish the site of exudation.

The observations on oxygen entry into the seed suggest that the husk usually provides the major barrier and that in undamaged seeds the only position at which oxygen could enter would be the tip at the end containing the embryo; here there is a crack in the coat and a plug of fibrous material. For seeds with other cracks in the husk, alternative paths for oxygen entry would be available and this might provide a further explanation for the 
Table I. Effect of oxygen on the exudation of soluble carbon from barley seeds

$\begin{array}{cc}\begin{array}{c}\text { Oxygen concn } \\ (\%)\end{array} & \begin{array}{c}\text { Exudation in } 24 \mathrm{~h} \\ (\mu \mathrm{g} \text { soluble carbon seed }\end{array} \\ 20 \cdot 8 & 19 \cdot 4 \\ 4 & 30 \cdot 4 \\ 0 & 32 \cdot \mathrm{I}\end{array}$

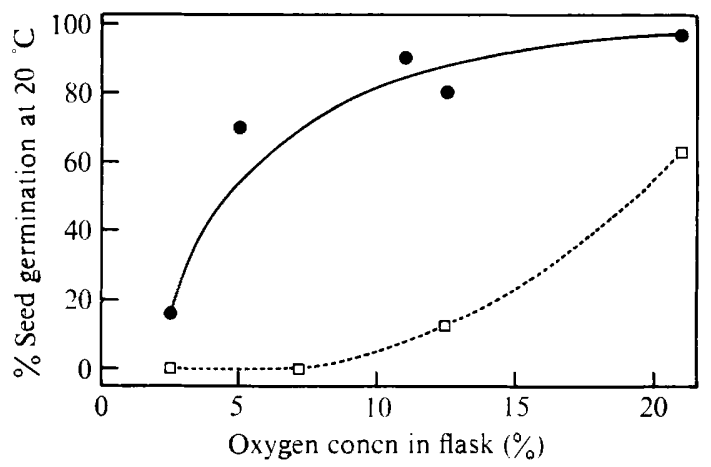

Fig. I. Effect of oxygen on barley seed germination in the absence ( $(\bullet)$ or presence ( $\square)$ of Gliocladium roseum.

absence of complete inhibition of germination described above. However, it could be that the layer beneath the husk, the pericarp-testa, is the structure which provides the barrier to oxygen diffusion as it was not possible to establish unequivocally that this layer was not damaged during the removal of the husk.

A major factor contributing to the ability of the fungus to prevent seed germination appears to be its successful competition with the seed for oxygen. Others have concluded from respirometric studies with antibiotic treatment of seeds that competition for oxygen is important in interactions between micro-organisms and seeds (Gaber \& Roberts, 1969; Heydecker \& Chetram, 197I; S. H. T. Harper \& J. M. Lynch, unpublished results). In 'anaerobic' soils, it is likely that microbial competition with the seed for oxygen would be particularly deleterious but this does not preclude the possibility that the microbial production of toxins is also important.

Although neither seed nor fungus grows under anaerobic conditions, a reduction in the supply of oxygen, which induces more soluble carbon compounds for fungal growth to be exuded by the seed, indirectly makes the seed more vulnerable to fungal colonization. This is consistent with the results of laboratory and field experiments with seeds of bean (Schroth \& Cook, 1964; Matthews \& Bradnock, 1968), cotton (Hayman, 1969), peas (Flentje \& Saksena, I964; Kerr, 1964; Matthews \& Bradnock, 1967, 1968) and soybean (Keeling, I974) which have shown that seeds producing the greatest amounts of exudates are those most susceptible to fungal attack. Seeds in a batch usually have different vigours (Heydecker, 1972) and this may explain why not all of them are affected by fungal stress in air.

The colonization of barley seeds by the pathogen Cochliobolus sativus is increased during anaerobiosis but $G$. roseum can successfully compete with it (Tyner \& McKinnon, 1964). The present studies indicate that this competition is of little practical value. However Azotobacter chroococcum can successfully compete with $G$. roseum without adversely affecting the seed; this effect is dependent on inoculum densities and germination conditions (Lynch, 1977b). Nevertheless it appears that treatment of seeds with suitable chemicals might be a more practical way of preventing the fungal colonization of seeds in the field.

The present study has examined some aspects of the interaction between the seeds of 
one plant species and a fungus. However, this interaction does not appear to be restricted to $G$. roseum and barley as we have found similar activity with another common soil fungus, Mucor hiemalis. In the field, the interaction would depend on the density of fungi to which the seed is exposed and this follows the concept of inoculum potential (Garrett, 1970).

We are grateful to Mr S. H. T. Harper, who made useful comments, and Misses Janet M. Marshall and Lynda M. Panting, who provided technical assistance.

\section{REFERENCES}

BARBER, D. A. (1967). The effect of micro-organisms on the absorption of inorganic nutrients by intact barley plants. I. Apparatus and culture technique. Journal of Experimental Botany 18, I63-I69.

Domsch, K. H. \& Gams, W. (1972). Fungi in Agricultural Soils, pp. 82-85. London: Longmans.

Ellis, F. B., Barber, D. A. \& Graham, J. P. (I975). Seedling development in the presence of decaying straw residues. Agricultural Research Council Letcombe Laboratory Annual Report, 1974, pp. 39-40.

FlentJe, J. T. \& Saksena, H. K. (1964). Pre-emergence rotting of peas in South Australia. III. Host-pathogen interactions. Australian Journal of Biological Sciences 17, 665-675.

Gaber, S. D. \& RoberTs, E. H. (I969). Water-sensitivity in barley seeds. II. Association with microorganism activity. Journal of the Institute of Brewing 75, 303-314.

Garrett, S. D. (1970). Pathogenic Root-infecting Fungi. London: Cambridge University Press.

GunN, K. B. (1975). An automated method for the determination of total organic carbon in root exudates. Agricultural Research Council Letcombe Laboratory Annual Report, 1974, pp. 76-77.

HAYMAN, D. S. (I969). The influence of temperature on the exudation of nutrients from cotton seeds and on pre-emergence damping-off by Rhizoctonia solani. Canadian Journal of Botany 47, 1663I669.

HeYdeCKeR, W. (1972). Vigour. In Viability of Seeds, pp. 209-252. Edited by E. H. Roberts. London: Chapman and Hall.

Heydecker, W. \& Chetram, R. S. (I97I). Water relations of beetroot seed germination. I. Microbial factors, with special reference to laboratory germination. Annals of Botany 35, 17-29.

KeEling, B. L. (1974). Soybean seed rot and relation of seed exudate to host susceptibility. Phytopathology 64, 1445-1447.

KERR, A. (1964). The influence of soil moisture on infection of peas by Pythium ultimum. Australian Journal of Biological Sciences 17, 676-685.
LYNCH, J. M. (1975). Ethylene in soil. Nature, London 256, 576-577.

LYNCH, J. M. (1976). Products of soil micro-organisms in relation to plant growth. CRC Critical Reviews in Microbiology 5, 67-107.

LYNCH, J. M. (1977a). Phytotoxicity of acetic acid produced in the anaerobic decomposition of wheat straw. Journal of Applied Bacteriology 42, 8I-87.

LYNCH, J. M. (1977b). Microbial interactions around imbibed seeds. Annals of Applied Biology (in the Press).

McCalla, T. M. \& Norstadt, F. A. (I974). Toxicity problems in mulch tillage. Agriculture and Environment I, I53-I74.

Matthews, S. \& BRADNOCK, W. T. (1967). The detection of seed samples of wrinkle-seeded peas (Pisum sativum L.) of potentially low planting value. Proceedings of the International Seed Testing Association 32, 553-563.

MatTHEWS, S. \& BRADNOCK, W. T. (I968). Relationship between seed exudation and emergence in peas and French beans. Horticultural Research 8, 89-93.

Pearson, R. \& Parkinson, D. (I96I). The site of excretion of ninhydrin-positive substances by broad bean seedlings. Plant and Soil 13, 391-396.

Schroth, M. N. \& Cook, R. J. (I964). Seed exudation and its influence on pre-emergence dampingoff of bean. Phytopathology 54, 670-673.

Simon, E. W. (I974). Phospholipids and plant membrane permeability. New Phytologist 73, 377-420.

Smith, K. A. \& Dowdell, R. J. (1973). Gas chromatographic analysis of the soil atmosphere: autometric analysis of gas samples for $\mathrm{O}_{2}, \mathrm{~N}_{2}, \mathrm{Ar}$, $\mathrm{CO}_{2}, \mathrm{~N}_{2} \mathrm{O}$ and $\mathrm{C}_{1}-\mathrm{C}_{4}$ hydrocarbons. Journal of Chromatographic Science II, 655-658.

Tyner, L. E. \& MCKinnon, B. A. (1964). Fungi of barley seed and their associative effects. Phytopathology 54, 506-508. 